\title{
Managing Communities of Co-creation around Consumer Engagement Styles
}

\author{
ERIC MARTINEAU AND ZEYNEP ARSEL
}

\begin{abstract}
How does co-creation create value for the firm and consumers, and how can firms manage co-creation communities more effectively? This article utilizes interview and online data collected from two firm-managed cocreation communities with differing span, trajectory, and success to understand how value is created for the firm and the consumers. We first establish four types of engagement styles based on how participants differ in their skill and community orientations. Then we describe how each group derives value from their co-creation activities and how these practices benefit the firm. Finally, we suggest guidelines to effectively manage these communities and address member needs and motives so that the firm can maximize value for all community stakeholders. Our work also provides insights on why some co-creation projects thrive and others do not.
\end{abstract}

n 2006, Wired magazine brought attention to a new type of marketplace actor that contributes to the value-creation process: the crowd (Howe 2006). Crowdsourcing, as defined by Kleemann, Voß, and Rieder (2008), is a process through which a profit-oriented firm outsources value-chain tasks to the public. Thus a firm can "leverage the collective intelligence of a community for a specific purpose" (Brabham 2012, 395). This is a part of a recent paradigm shift from producer innovation to consumer innovation (Kozinets, Hemetsberger, and Schau 2008; Von Hippel 2009; Baldwin and von Hippel 2011). From a marketing point of view, crowdsourcing adds value with minimal outlay. The quality and the quantity of work amateurs can produce are now comparable to that of professionals (Conley and Tosti-Kharas 2014; Kohler 2015). Furthermore, Brabham (2009) suggests that outcomes of crowdsourcing are superior to what corporations can achieve using internal resources. This is because the collective intelligence surpasses those of individual specialists (Howe 2008). Crowdsourcing projects enhance the value proposition of consumer goods while being financially viable (Djelassi and Decoopman 2013) and "answer to fast-changing user needs, shorter product life-cycles and an increasingly competitive climate" (Kohler 2015, 65). This is in line with existing research showing how innovation and value are created with the help of consumers (Terwiesch and Ulrich 2009).

Despite consumers being one of the major stakeholders, much of what has been written on crowdsourcing utilizes a firm-centric perspective, viewing participants as labor, and prioritizing resource implications to the corporation (Kleemann et al. 2008; Schenk and Guittard 2011). In that sense, crowdsourcing is placed within a tripartite choice set of problem-solving workforce: in-house talent, outsourcing to a professional contractor, and crowdsourcing. Still, crowdsourcing differs in the sense that tasks are contracted to volunteer producer-consumers. In this article, we employ a complementary perspective to existing studies by looking at crowdsourcing from the participants' view, underscoring their role as not only producers but also connected prosumers. ${ }^{1}$ Why would people willingly devote their time and efforts toward the development and promotion of a product for a company without any financial return?

Existing research suggests that people who engage in crowdsourcing are creative consumers with artistic talents not utilized through their daily jobs (Kozinets et al. 2008). Brabham (2012) further suggests that crowdsourcing also

Eric Martineau (eric.martineau@collegelasalle.com) is a lecturer, Department of Fashion Marketing, LaSalle College. Zeynep Arsel (zeynep.arsel@concordia.ca) is an associate professor and Concordia University Research Chair in Consumption and Markets, Department of Marketing, John Molson School of Business, Concordia University. The authors thank Anissa Pomiès, Biliana Necheva, Jonathan Bean, Marie-Agnès Parmentier, Pierre-Yann Dolbec, Ulrike de Brentani, the editor, and two reviewers for their constructive feedback at various stages of this project. The authors also extend their gratitude to the people of Mode Locale (name changed), who gave them the opportunity to conduct participant observation. This article is based on Eric Martineau's MSc thesis and was funded by Fonds de Recherche du Québec-Société et Culture.

1. The terms co-producer (Etgar 2008), prosumer (Humphreys and Grayson 2008; Xie, Bagozzi, and Troye 2008; Beer and Burrows 2010), and working consumer (Kleemann et al. 2008; Cova and Dalli 2009) are often used to refer to these volunteer participants who rarely receive compensation. From these we have chosen prosumer as our preferred label.

JACR, volume 2, number 2. Published online March 14, 2017. http://dx.doi.org/10.1086/691145

(C) 2017 the Association for Consumer Research. All rights reserved. 2378-1815/2017/0202-0006\$10.00 
is an avenue for self-selected professional-amateur hybrids who are looking for opportunities. Literature on innovation has also determined that lead users have an intrinsic desire to provide firms with recommendations appealing to their sense of curiosity and showcasing their talents (Mahr and Lievens 2012). To fulfill their passion and need to explore their talents, these individuals turn to online communities. In other words, while generating value for the firm, the crowdsourcing activity also benefits the consumers. Whereas co-creating can be seen as a way for firms to recruit creative labor for product and service design, it is also creative leisure for the participants. Yet, there has been no systematic investigation on the consumer side of the process, and despite widespread assumptions in managerial literature, we still don't know how participants derive nonmonetary benefits through co-creation. In fact, Zhao and Zhu (2014) point out that the number of academic articles on this topic is relatively small compared to industry reports and popular pieces, and they call on researchers to further investigate participants' motivations in involvement on these platforms. In addition, as highlighted by Hossain and Kauranen (2015), there is a need for theoretically based guidelines to align these motivators with value-generating activities for the firm. Our work addresses this gap.

Our focus is a specific type of crowdsourcing: communities of co-creation. These are projects that involve complex tasks requiring creativity and specialized skills as well as intracommunity practices (Schau, Muñiz, and Arnould 2009) that create value. Rather than projects relying on routine, anonymous, and unskilled task-based activities such as Mechanical Turk, these communities foster innovation through collective participation. We also prefer co-creation as our nomenclature because it aligns with the theoretical shifts in value literature that we engage with. Empirically, we explore two projects with different spans, community development, trajectory, and success: Threadless and Mode Locale (name changed). Grounded in these two cases, we first provide a categorization of engagement styles based on two orientations: use and legitimation of skills, and degree of community affiliation. Building on this, we describe how each group derives value from their co-creation activities and how these benefit the firm. Then we provide practical guidelines for managers to utilize co-creation projects and maximize value for all stakeholders through better community management. We also provide insights on why some co-creation projects thrive and others do not. What are the barriers for some consumers to participate in these activities? Moving forward, what can be learned to better develop success- ful co-creation programs and manage co-creation communities? This article addresses these questions; but first, we would like to unpack the theoretical foundations of our typology.

\section{THEORETICAL FOUNDATIONS}

\section{Prosumers and the Firm Value Chain}

The role of consumers in the value chain have changed from passive audience to active participants (Prahalad and Ramaswamy 2000; Payne, Storbacka, and Frow 2008; Vargo, Maglio, and Akaka 2008; Cova and Dalli 2009). Prosumption is defined as "asking individuals to simultaneously play the role of consumer and producer" (Humphreys and Grayson 2008, 964), thus participating in the value chain. The enjoyment prosumers get from participating in a project and the quest for creating products that incorporate their preferences, especially in the case of services (Etgar 2006), act as motivators. Beer and Burrows (2010) suggest that prosumption is facilitated by the emergence of craft consumption (Campbell 2005). Today, this extends beyond private practices; consumers are contributing to collective craft. This movement also exemplifies the growing trend of consumers seeking experiences rather than product performance, where the experience is co-created by a network of actors (Lusch and Vargo 2006; Vargo and Lusch 2016).

On a product life-cycle curve, co-creation engages consumers from prior to the launch of a product to post-purchase. Humphreys and Grayson (2008) elaborate on the value chain further: Those creating primarily use value, "e.g., when they [consumers] dispense their own soft drink at a fastfood restaurant" (Humphreys and Grayson 2008, 970) do not alter the traditional roles. Prosumers alter the value chain dramatically when they perform tasks that add exchange value such as contributing to its design. In some cases, prosumers will purchase the good (Etgar 2006, 2008; Humphreys and Grayson 2008; Beer and Burrows 2010), as personalization is an opportunity to give feedback to the seller and determine product or service attributes. In other projects of co-creation, however, people do not necessarily purchase the final product or service (Howe 2006), such as those who helped Netflix with its algorithm or people who solved scientific puzzles for Fold.it (Howe 2008), despite the fact that they voluntarily contribute to value creation. Furthermore, communal practices increase loyalty and ambassadorship (Algesheimer, Dholakia, and Herrmann 2005), provide alternate methods to develop new products (Mladenow, Bauer, and Strauss 2014), and co-create brand meanings (Bagozzi and Dholakia 2006; Schau et al. 2009). These all ex- 
tend the value-creation process to post-purchase. However, like all communities of consumption, co-creation communities are not monolithic entities whose members contribute the value chain in the same manner. Therefore, we need to better understand how participation is patterned across prosumers.

\section{Extending Kozinets's Typology of Community Participation}

Understanding how consumption communities operate is an important step to begin exploring value co-creation, as these projects are built on community bonds (Kozinets et al. 2008; Schau et al. 2009; O'Hern and Rindfleisch 2010). While originally discussed in the context of brands (Muñiz and O'Guinn 2001), consumption communities are further expanding into more complex forms such as communities of co-creation and co-production where "consumers participate in the performance of the various activities performed in one or more of these [production] stages" (Etgar 2008, 98).

One of the earliest studies in communities is Kozinets's (1999) work on tribal marketing. He suggests segmenting online communities for better understanding of their practices. According to Kozinets, consumers develop a deeper identification with the community through two interrelated factors: relations with the consumption activity, and relations with the virtual community. These two dimensions then map into four distinct types of memberships: devotees, insiders, tourists, and minglers. Our work revisits this typology and adapts it to the communities of co-creation where skills are particularly relevant. We argue that, like all online communities, communities of co-creation need to be better understood in terms of their structure and patterns of relationship to the community. In co-creation communities, not everyone has same level of social ties with the community, nor do they possess, or are willing to invest, the same level of skills that are relevant to the creative project. While this may be less important for routine tasks such as those involving MTurk projects, in co-creation, skills matter.

Our revisit of Kozinets's work addresses a shift from general interest consumption activities to skill-based co-creation. We agree that his typology still applies to communities of consumption in the broader sense; however, we suggest a modified approach to bring more specificity to co-creation communities. We therefore propose replacing the centrality to consumption activity with skill orientation to reflect the nature of co-creation activity. We retain the ties to community dimension as is but relabel it as community orientation. We further reinforce our theoretical basis by better linking this two-fold typology of engagement to existing theories on communities. In addition, we suggest that engagement should not just be limited to existing levels of skills and ties to community, but also should incorporate community members' willingness to pursue acquiring more skills and social ties in the future. In that light, we suggest that engagement can be theorized through a twofold lens of contextualized (community-dependent) social and cultural capital. We unpack this argument in the next section.

\section{A Capital-Based Theory of Community Engagement}

Engagement is a frequently used but still contested concept (Van Doorn et al. 2010; Brodie et al. 2011; Vivek, Beatty, and Morgan 2012). Engagement with a firm can happen at many levels and involve multiple dimensions from both the firm and consumer side (see Van Doorn et al. [2010] for a review). What particularly concerns us is the engagement with the co-creative process and the community practices that surround co-creation. In our use of the term, we employ a behavioral, experiential, and relational perspective and follow the working definition proposed by Brodie et al. (2013). Accordingly, we define engagement as the degree to which a person participates in experiential and communicative processes of a co-creation community. Building on existing work on communities, we further argue that in communities of skill-based practices, these processes can be viewed through the lens of social and cultural capital.

Social capital is "relationships of mutual acquaintance and recognition" (Bourdieu 1986/2011, 21) and is developed through networks formed within a community as "participants act together and pursue shared objectives" (Wiertz and de Ruyter 2007, 351). As the nature of the communal goals requires participants to collaborate with one another in order to complete tasks, they also serve to build connections. These practices are governed by voluntarism, reciprocity, and social trust (Mathwick, Wiertz, and De Ruyter 2008). As Nahapiet and Ghoshal (1998) state, participants derive their social capital both from relationships built with other community members and with the commercial entity. Moreover, Wiertz and de Ruyter's (2007) findings state that the quantity of interactions is related to the perceived value of the content shared, the feeling of reciprocity, and the relationship between members. We use this as the dimension that drives one's community orientation.

Online communities also are resources for deployment of cultural capital. Cultural capital (Bourdieu 1986/2011) 
is tacit skills and ability to relate to a field bound by practice as well as the recognition and status that one receives through these skills and ability. In communities of co-creation, these are skills relevant to the task at hand, including the ability to relate to the aesthetic norms of the community contextualized within a taste regime (Arsel and Bean 2013). These communities are usually established in ways to allow users to be visible, thus utilizing people's existential need for recognition (Cauquelin 2003). Through profile pages, participants in online communities can not only showcase their brand moments (Cova and Pace 2006) but also use them as badges within the community (Schau et al. 2009). We use this as the dimension that drives one's skill orientation.

As in most fields in social space, cultural and social capital are interrelated and co-constitutive in generating status and recognition within the corresponding context, acting as symbolic capital (Bourdieu and Wacquant 1992). This is analogous to how individuals position themselves in organizational fields (Parmentier, Fischer, and Reuber 2013). Members achieving status within the community accumulate cultural capital; in return, their status elevates them to focal members (McAlexander, Schouten, and Koenig 2002). Recursively, social capital allows access to resources and increases capacities (Nahapiet and Ghoshal 1998). These coconstitutive practices create value not just for the prosumers but also for the firm (Schau et al. 2009). To understand how capital-based engagement generates value, we employed a comparative case analysis. We use two firms that employ co-creation, with different histories and successes. Both are classified as crowds according to Kozinets et al.'s (2008) typology: innovation activity is dispersed across a diverse set of participants. Furthermore, within these cases, our participants vary in their skill orientations and community engagements. We discuss this empirically after we summarize our methodology.

\section{METHODOLOGY}

\section{Participant Observation}

The first stage of data collection included participant observation in Mode Locale (name changed to protect the identity of research participants and the company), a local start-up that had hosted co-creation sessions with prominent figures in the local fashion community. Through its Facebook page, the company broadcasted photos and videos of the design process, and the community members were invited to suggest (or vote on) creative decisions. The first author, who disclosed this research project to the company, was permitted to conduct fieldwork while volunteering as a marketing intern. The goal of the internship was to expand and co-create an entire collection. Prior to the internship, Mode Locale had hosted two other successful co-creation sessions. This internship opportunity gave us hands-on involvement with the co-creation and access to documentation and participants for all sessions; however, the efforts were ultimately unsuccessful. Moreover, several attempts to build a creative community did not amount to anything conclusive. The project was terminated after a failure to achieve necessary engagement levels to foster enough creativity to build a collection. While unfortunate, this experience provided us with the invaluable opportunity of observing a project that didn't succeed. We will discuss these observations in our implications section. This fieldwork lasted 3 months, for a total of 164 hours of participation.

\section{Netnography}

After the demise of Mode Locale, we pursued a more successful case for contrast. We chose Threadless, an apparel company described as a classic example of co-creation (Kozinets et al. 2008). The company has been in the spotlight due to its success in utilizing this business model (Chafkin 2008). At the time of this writing, there are more than 3 million voting members (Nickell 2014) who have submitted over 522,000 designs (Threadless 2015). Prior to interviewing Threadless members, the first author familiarized himself with the culture of the community. Netnography guidelines (Kozinets 2002, 2009) served as our roadmap. The first month was spent as a passive member, during which he logged on daily to the message boards to better understand the rules and rituals these users have created and to document recurring themes. A better understanding of the dynamics of the community emerged once he began interacting with users. His first step of active participation included submissions and critiques of others' submissions. After that, he started posting to community boards. Boards were selected at first by the richness in conversation content and the author's own level of familiarity with each topic. Boards on off-topics or simple critiques of shirts seemed to be more approachable to begin with and allowed for an easier integration with the community. Our extended experience with the community also permitted us to better tailor our interview questions, put our participants at ease by relating to the culture of the community, and effectively communicate using their jargon. 


\section{Interviews}

Fourteen interviews were conducted across two co-creation projects. Interviewees were members who responded to researchers' calls for participation in the community forums. The first author conducted all interviews over videoconferencing, or in person. The total duration of interviews was 318 minutes. Unlike identity interviews that seek circular narratives that seek tensions, ours were shorter and focused on the task at hand and more pragmatic questions regarding the co-creative process. The format of the interview still allowed for an understanding of the interviewee's lifestyle and personality, with preliminary life history questions. This also served as a way to lower the tension and establish rapport. Our questions covered work, interests in art and design, and the daily lives of our participants. These were followed by co-creation-specific questions that inquired about their involvement with Threadless, their impressions of the brand, and their feelings toward the community. These data were collected and analyzed using an iterative process. Each interview was first analyzed individually. We then moved to the whole data set to look at patterns and differences across the participants (Thompson 1997). We continued making interviews and revised interview questions based on emergent findings (Spiggle 1994). We continued this process until the theory became solidified.

\section{FINDINGS: HOW DIFFERENT STYLES OF ENGAGEMENT CREATE VALUE FOR CONSUMERS AND THE FIRM}

As introduced earlier, we build our framework on two orientations: skills and community. We describe skill orientation as a tendency to invest in and utilize skills relevant to the cocreative task. We use our participants' self-reports of skills and their desire to further develop these skills to map them in this category. Those who are of high community orientation show markers of communities as identified by Muñiz and O'Guinn (2001). These two dimensions contribute to four unique styles of engagement with the co-creation project as summarized in figure 1 .

Our framework revisits Kozinets's (1999) call for better understanding of virtual communities of consumption by bringing more specificity to the emergent context of cocreation communities. Second, we extend his work by linking engagement styles with value-creating practices for both the consumer and the firm. In the following sections, we explore these four styles and then discuss how managers of

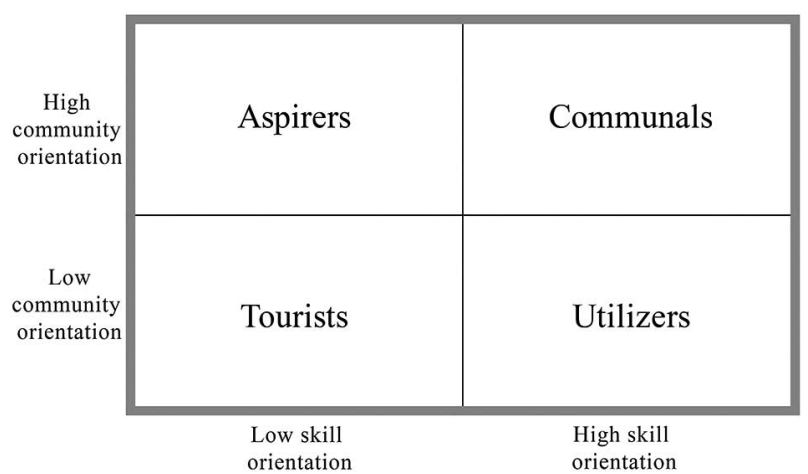

Figure 1. Participant engagement styles, where the vertical axis shows increasing level of community orientation, and the horizontal axis shows increasing skill orientation.

co-creation communities can better address member needs and maximize value for the firm and participants. Table 1 summarizes the profile of our sample with a singular quote that captures their participation style.

\section{Communals}

Communals have a desire for both using (and building) skills and engagement with the community. Four participants (Marie, Henri, Josh, and Patricia) were identified as communals. These members have internalized the community rules, norms, and aesthetics. Furthermore, they can identify other members through brand use in public through spotting the company's unique aesthetic sensibility and oneof-a-kind designs (which are not always recognizable by less invested members) and demonstrate consciousness of kind (Muñiz and O'Guinn 2001). This serves to delineate the most knowledgeable and involved members from those who aren't, and demonstrates contextualized cultural capital in action:

Sometimes I go, "hey, that's a nice shirt." I've learned that when you go "hey Threadless shirt" most people are like "huh what?" they just a little freak out. People either know what they are wearing, or sometimes they were just given it, or sometimes they are more of an occasional buyer. (Henri, 500+) ${ }^{2}$

Patricia $(200+)$ also speaks of how she frequently gets stopped by other communals when she wears Threadless

2. The figures in parentheses indicate the number of Threadless T-shirts a participant owns, whenever the information is available. 
Table 1. Engagement Styles of Each Research Participant

\begin{tabular}{|c|c|c|c|c|}
\hline Name & Age & Occupation & Engagement Style & Exemplary Quote from Interviews \\
\hline Alexandria & 23 & Student & Aspirer & $\begin{array}{l}\text { "It [the T-shirt] is interesting because you're pretty much the only one around } \\
\text { here who has it." }\end{array}$ \\
\hline Jessie & 29 & $\begin{array}{l}\text { Performance } \\
\text { artist }\end{array}$ & Aspirer & $\begin{array}{l}\text { "I could say something, and people would listen to it. I don't think it would } \\
\text { mean a lot." }\end{array}$ \\
\hline Henri & 24 & Entrepreneur & Communal & $\begin{array}{l}\text { "That's how I can help, that's the least I can do for people putting so much effort } \\
\text { into all their work on Threadless." }\end{array}$ \\
\hline Josh & 21 & Student & Communal & $\begin{array}{l}\text { "If you ask, well all my friends, and you talk about Threadless, you are talking } \\
\text { about me." }\end{array}$ \\
\hline Marie & 28 & Editor & Communal & "You get to build relationships." \\
\hline Patricia & 25 & Art director & Communal & "We kept in touch on Twitter, Facebook . . everyone has their outlets." \\
\hline Jane & 25 & Student & Tourist & "They have $\$ 10$ sales sometimes so I just end up buying a bunch when they do." \\
\hline Lanette & 23 & Nonprofit & Tourist & "I had forgotten I had done it." \\
\hline Marc & 31 & Student & Tourist & $\begin{array}{l}\text { "Everybody wants to interact with their keyboards and their laptops. They just } \\
\text { want to say something." }\end{array}$ \\
\hline Carrie & 27 & Designer & Utilizer & $\begin{array}{l}\text { "The designs were brainstormed, but in the end, I did everything in my living } \\
\text { room." }\end{array}$ \\
\hline Pietra & 32 & $\begin{array}{l}\text { Administrative } \\
\text { assistant }\end{array}$ & Utilizer & "I fail at being Threadles-sy . . . I think I haven't really gotten it." \\
\hline Ronnie & 26 & $\begin{array}{l}\text { Administrative } \\
\text { assistant }\end{array}$ & Utilizer & $\begin{array}{l}\text { "I just felt the way Threadless is built, it's a lot easier for people to get your stuff } \\
\text { out there for people to see." }\end{array}$ \\
\hline Tamisha & 41 & Self-employed & Utilizer & "They helped me come up with the concept-making it more realistic." \\
\hline Terry & 31 & Graphic artist & Utilizer & $\begin{array}{l}\text { "It's not an exceptional design, but it's not the same type of T-shirt you nor- } \\
\text { mally see on Threadless." }\end{array}$ \\
\hline
\end{tabular}

in public. In her case, again, core members demonstrate consciousness of kind only when they have the skills to identify the object correctly:

Seeing a Threadless T-shirt on TV, you recognize it, because you just know what the artwork looks like... you just know they're from Threadless, and you'll be walking down the street and you'll hear "Threadless," and you're like "Yeah."

Communals hold rituals and traditions, an important characteristic of a brand community (Muñiz and O'Guinn 2001). Meet-ups allow members to interact with each other and build social capital. The sense of moral responsibility, the third characteristic of community (Muñiz and O'Guinn 2001), is also high toward other community members. Members have a sense of debt toward Threadless (and its community) for the opportunity and critiques they have received on their work. The currency with which this debt is returned is again through creative input to other members in an empathetic manner (Schau et al. 2009; see fig. 2). For example, "Promote your design here, I will help you score and comment your design" is a thread that has been going on for 5 years, with 2,925 comments at the time of writing. Henri $(500+)$ further explains:

I was like “That's great, you don't have to approve anything I say, that's fine; but I'm going to be perfectly honest with you. So that's how I can help. That's the least I can do for people putting so much effort into all their work on Threadless." And that's what I mean by the least I can do, I've gotten so much out of Threadless that I feel that's the best way I can pay Threadless back and the community of ours.

These participants' bonds runs deeper than designing shirts; they know about each other's lives, stay updated through various social networks, and plan trips to visit each other. When the member quick-brown-fox travels to San Francisco, he starts a Threadless thread to ask what to do in this city, instead of visiting sites specifically tailored for touristic advice such as Yelp or Tripadvisor. For them, Threadless is a community of like-minded individuals who subscribe to a singular taste regime (Arsel and Bean 2013) whose reach 


\section{\#Help, Newbie rejected. Any advice on how to make my design better? \\ by ecy96 posted Oct 09, 2015 in Tips \& Tricks 4 Comments}

Hi my name is Estefania , I'm new on threadless and on the last couple of days I have submitted 2 different designs for the "mean girls" contest. I knew it was hard to get your designs admitted on the first submissions (maybe harder because I have no studies or experience in graphic design) so I decided to hold on until I felt I was good enough, when I was happy with the results I sent it and of course I got rejected. Then I changed a few things and got rejected again. I could really use some help from experienced people so if you guys could offer me any advice on how to make my drawings better or how to get them approved I would appreciate it very much. On both emails I received I was told: "Your submission was declined because we feel your idea could use a little more work to be up to the standard that will give it the best shot" Does that mean the concept was bad, or was it the drawing? Maybe both, I would love to hear some critique about both.

Open to suggestions.

Thanks in advance for your help and patience (again, I'm new on this).

(I am using Sketchbook Pro 6 by the way, If there's any other program similar or better please let me know)

\section{Hera are my designs:}

First one:

https://41.media.tumbir.com/782cb97aaebafd89484a2c4eddd51b13/tumblr_nvz8u1eVxl1t31ejvo1_1280.jpg

Second one:

https://40.media.tumblr.com/2c614691c3f2ed50a143cf5b751d607e/tumblr_nvz8u1eVxl1t31ejvo2_1280.jpg

Y Tweet

$G+1$
ABOUT THE BLOGGER

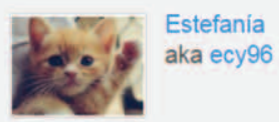

View my profile page

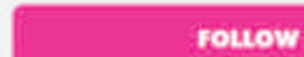

RECENT POSTS

Oct 09: \#Help, Newbie rejected. Any advice on how to make my design better?

is

rockthejukebox on Oct 9'15 @20.07

Welcome and congrats for submitting your first designs. I think your concept is fine. The first one is stronger, but there's too much going on with all the different fonts and the background pattern. Pick one font that best represents Cady's voice and consider a pink t-shirt instead of the circles in the background. Also, try mocking up your design on a t-shirt to avoid cutting off things like your speech bubbles. Best of luck!

heykimby on Oct. 9'15 @21.06

I think you could simplify the design a lot more and as a result the concept would be much clearer.

?.

croncallo on Oct.9'15@21.18

try to change the font of some words for a more attractive one, I think the idea is good but there is a difference in a illustration as an image and as a t-shirt design. I agree with the guys to simplify it. specially the back ground. Also is always to show them as a actual part of a t-shirt to get a better idea how it would look. Good luck!

Figure 2. Example of a forum post wherein communals empathize with aspirers.

goes beyond the task at hand: designing T-shirts. Members sustain contact over periods of time, which "enables friendships to expand above brand boundaries" (Schau et al. 2009, 34):

We now talk outside of co-creation; we try to make cool sites. We now e-mail each other, you know Facebook, outside Threadless projects. I probably have friends on every continent now all thanks to Threadless, I know about their personal life. It is more than just designing. (Henri 500+)

Out of all groups, communals are the most engaged and spend the most time on the site. Through affiliation, acknowledgment, and networking, communals continuously build symbolic capital; in this case, votes, followers, and 
sold-out T-shirt designs (see fig. 3). Generating and deploying capital are the reasons why they return to the site often and maintain connections with members; therefore, they continuously perform efforts of sociability and exchanges that perpetuate recognition (Bourdieu 1986/2011). Our data show that communals perform all 12 community value-creation practices identified by Schau et al. (2009). For example, staking can easily be observed by clearly delineated subcommunities and hierarchies such as the pop-culture reference group, the abstract art group, or the slogan adepts (Threadless 2015), most of which arise organically by members. Badging (Schau et al 2009) occurs when a participant gets a design printed and receives a crest on his or her profile page. Since only a very small percentage of the shirts sub-

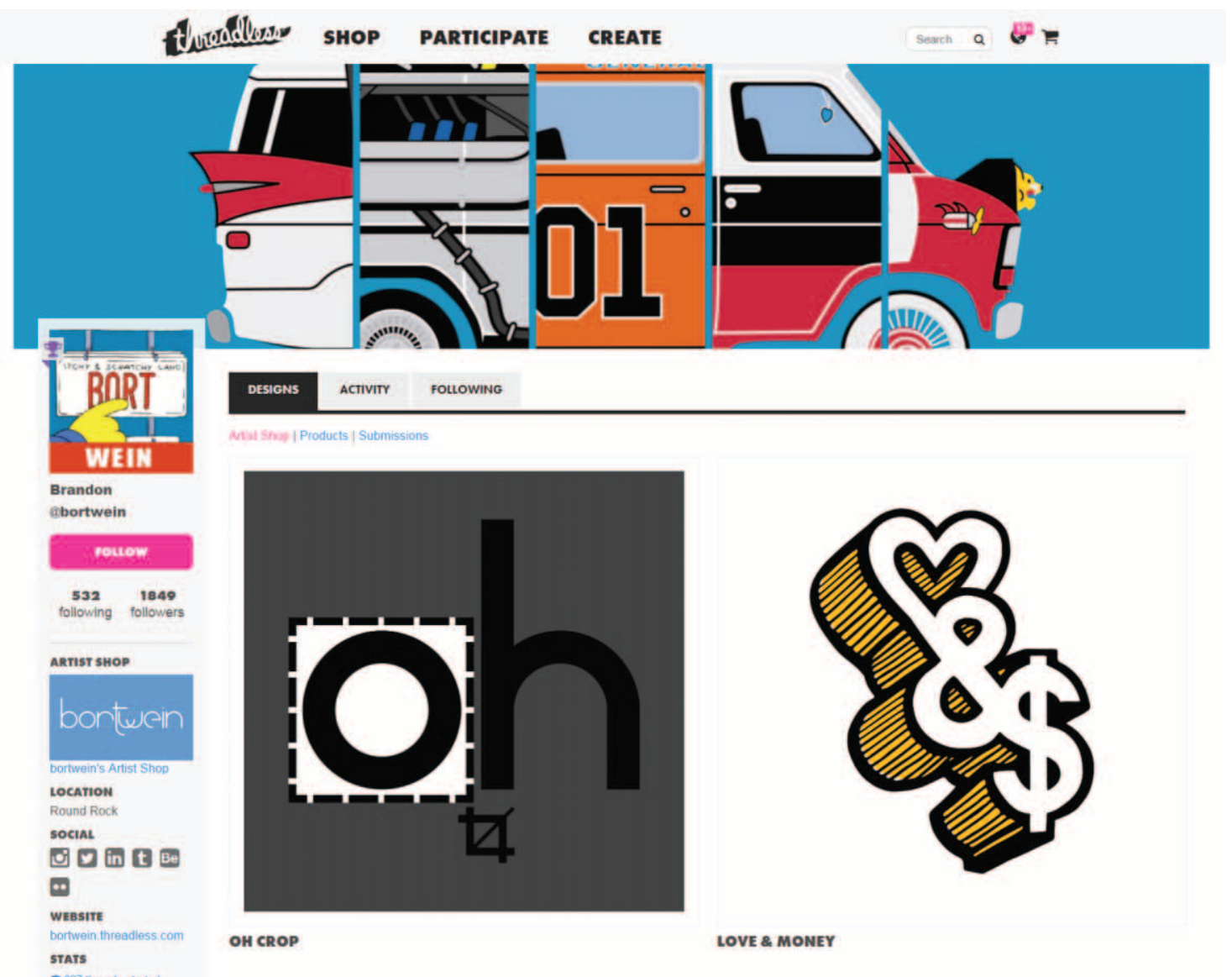

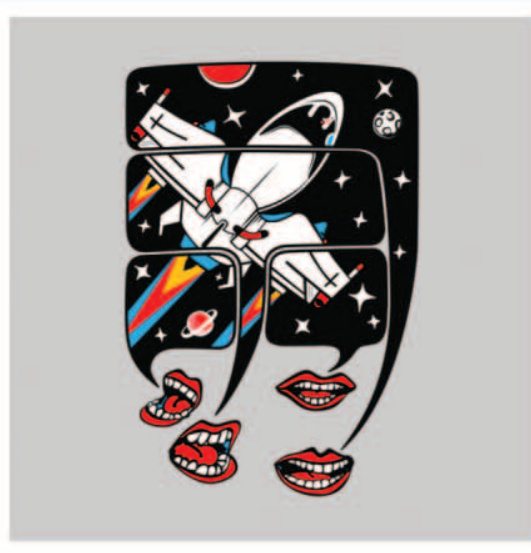

LETS TALK ABOUT SPACESHIPS

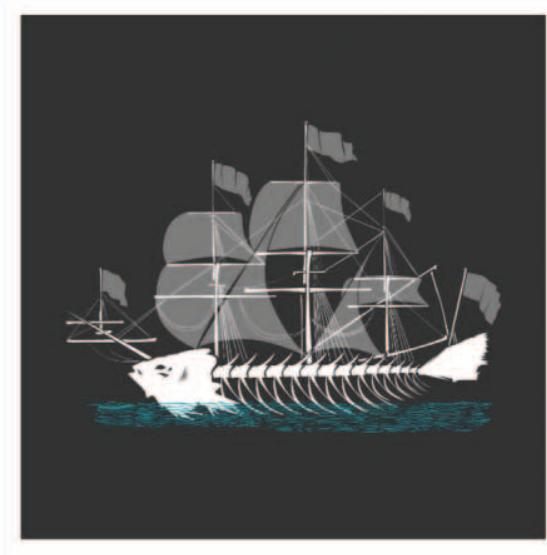

CUTTER FISH

Figure 3. Profile page of a communal. 
mitted ever make the cut, this represents approval from peers, and marks significant symbolic recognition. All our communal interviewees have spoken highly about their experience receiving their first "print" (their first design to win a contest). This is a milestone (Schau et al 2009) that marks significant capital in the community:

I got thrown into the mix with these Threadless legends that I got to work with. So here I am, I'd never had a print, I didn't work there or anything and we submitted a shirt to get voted and we just ended up winning. Like, wow! (Patricia 200+).

Through self-expression and voicing of opinions (Etgar 2008), communals are creating value for Threadless in the form of new product development (Humphreys and Grayson 2008). Second, they add value by contributing to the brand narratives. Third, evangelization and justification of one's commitment to nonmembers are also practices that create value for the firm (Schau et al. 2009). The communals act as brand ambassadors and as mentors to the novice participants, as in the case of a newbie seeking help. This is important because Threadless rarely uses advertising, and its growth in the early 2000s has been achieved through word of mouth (Chafkin 2008).

\section{Utilizers}

Utilizers are participants with weak communal connections, or little desire for such connections, but high skill orientations. They derive experiential value from participation as well as accumulating skills. The utilizers are creating value for the firm through customization and commoditization, but they are not doing this due to their commitment or obligation to a collective. Rather, their goal is to practice and hone their skills. Five interviewees were classified in this group: Carrie, Tamisha, Ronnie, Terry, and Pietra.

Whereas utilizers might feel disengaged from the forums and other members of the community, they use and value the resources created by others. Some also participate to move forward in their career, like Tamisha, a professional designer who got involved with Mode Locale as a way to gain exposure. For others, the experience of designing is the end goal. For example, Terry $(50+)$ mentions how he will work hard on designs, but once he submits them he does not actively pursue other community members to vote for his: "I've worked on many things, but I never pushed hard to get them on Threadless, it was all just design that I made for fun." Pietra acknowledges the tastes of the community although she doesn't feel the need to tailor to it, to be a part of it, or to win a badge; she just wants to design and learn new skills:

You already try to make things that fit, but really for me I think I just really like to do things the way that I like to do them, part of it is when I imagine something, I like to have it done the way that it's in my head. . . . The Threadless forums are so powerful because people make tutorials and huge blogs where people just basically explain everything [to you].

These individuals participate independently and see the community only as a resource for know-how, interacting on a need-only basis such as learning skills for using design software. Since co-creation provides little financial reward, and only to contest winners, the enjoyment of the process and improving one's craft act as motivators. This mirrors the findings of Roth, Brabham, and Lemoine (2015), who show that internalized extrinsic motivators such as status, recognition, friendship, and skill development are superior to extrinsic motivators such as financial compensation in recruiting new members to crowdsourcing communities. Furthermore, financial motives to participate in contests are frowned upon, valorizing participating for the sake of art, skill building, and enjoyment, as noted in the response by utilizers to the one-time-only poster Oberon580:

\section{Oberon580 posted Jul 29, 2013, in General}

How much can an artist earn if their design is selected? I just want to know before I work really hard and find out the payment is only $\$ 50$ dollars or something.

taz-pie on July 29, 2013, at 23:25:03

how about you design something cos you love it, instead of for some monetary reward? there are people that have refined their craft here for YEARS without being printed. threadless is not a getrich-quick scheme.

mip1980 on July 30, 2013, at 01:07:18

I agree with Taz, if your here for some quick money, you may end up disappointed

melmike on July 30, 2013, at 02:04:44

haha, I get where both arguments are coming from. I think the best designs should reward the designers with big dollars, but at the same time, no one unwill- 
ing to put in long, unrewarded hours will survive here. I spent 5-8 hours everyday for 30 days straight on my Mickey Mouse design. If you can't take pleasure from the work itself, then yeah, Taz is right, you're not going to stay here long.

vectored_life on July 30, 2013, at 03:26:40

I have improved my skills tremendously as well. Don't get me wrong, I want some cash too but meh.

Whereas the creations of the communals aim at aligning with the perceived communal aesthetics, utilizers will produce designs according to their liking, thus bringing more diversity to the aesthetics of the community. This type of customizing (Schau et al. 2009) keeps the brand evolving and thus creates value for the firm.

\section{Aspirers}

Aspirers are less skilled than the first two, though many wish to gain more skills. Among our research participants, Alexandria and Jessie are classified as aspirers. Their participation is limited to small tasks that extend to giving their opinions or ratings to shape the final product but not directed to complex tasks and connections that generate symbolic capital within the community. Jessie states that she likes voting, but when it comes to commenting or giving critique, she stands back: "I mean I don't really have that much to say. They are the pros." This is in line with Kozinets et al.'s (2008) findings showing that first-order members innovate and create content and that second-order members, in this case the aspirers, simply evaluate the content, which requires less work and skill. For firms, collective voting by aspirers helps to calibrate average preferences. More importantly, this group consumes the end product. While communals and utilizers view consumption of the end product as distinct (and even irrelevant) from the creative task, aspirers use both their limited participation and the consumption of the product as a way to engage with the company. Throughout her interview, Alexandria discusses how she feels like a part of the community and how she understands the aesthetics of Threadless. Yet later she confesses that she doesn't possess the skills or capital to relate to the craft like a communal:

I've never commented. If I rate five, it means I like it, and the same with a one. I guess I don't find myself prepared or educated enough to say, "hey you should put more colors!" You know, to make an educated, constructive criticism, rarely I have something to say. Like who am I to say something like that?

Aspirers perform community practices such as staking (Schau et al. 2009), recognizing the various subgroups within the community and their own rank within. Although their participation is restricted due to a self-described lack of skills, they badge their membership outside the creative platform: "I have said to a few people on the street like 'Hey Threadless!'. . . so we're kind of insiders" (Alexandria). While not possessing the skill-based resources to have high status in the community, they are claiming affiliation with its members. The company's merchandise becomes an objectified form of capital (Bourdieu 1986/2011) to show consciousness of kind (Muñiz and O'Guinn 2001).

Members of this group bring value to the firm through consumption and feedback practices. In co-creation, a collective effort "enhances the chances of generating useful ideas" (Hossain and Kauranen 2015, 11). Through their purchase, they are hoping to associate themselves with the values and meanings associated with both the firm and the community. Jessie says: "Threadless has a real hipster feel to it. I like it because I'm kinda hipster too." By proselytizing the brand (Schouten and McAlexander 1995) and showcasing it to others, they are also acting as brand ambassadors. We consider aspirers to be a strong customer base for Threadless, a transitional step for communals, and a necessity for the firm's financial stability.

\section{Tourists}

Tourists rank the lowest in terms of engagement. Among our participants, Jane, Marc, and Lanette were classified as tourists. They take part in the creativity project without investing many resources into it. Their participation occurs if it fits with their already established routines, such as voting on others' designs and receiving experiential value from this. Thus, co-creation activities are performed during downtime and without deep commitment. They purchase the final product without paying much attention to the process surrounding its production. Members of this group do not see themselves as a part of the creative practices in the community of a product and even sometimes qualify their participation as "killing time" (Jane, 30+).

Jane needs to be reminded to visit Threadless through the monthly e-newsletter regarding sales. Moreover, she states that she is unfamiliar with the creative process a shirt goes through before sale. Her participation is limited to rating shirts, usually when nudged: "Well once in a while, when 
I have nothing to do, especially when they have a sale, I'll just log on and then end up staying for a few hours rating shirts." Lanette didn't prioritize her involvement with Mode Locale: "I had kind of forgotten I had done it; and before we chatted, I didn't even realize I was part of co-creation." Although she had posted a few comments during one of Mode Locale's co-creation sessions, she did not inquire about the outcome of this project until our interview: "To be honest, I haven't [followed up], I haven't had a chance, which sounds crazy." Mode Locale's co-creation session was on the company's Facebook page and was part of Lanette's daily social media activity. She conflated the co-creation with her online socializing, thus not realizing what her participation entailed and contributed to a company's surplus value. Neither interviewees interacted with others in the community. They worked, without knowing that they did.

Tourists bring value to the firm in two ways. First, while it was impossible to get current Threadless membership figures - the last reported figure was 3 million (Nickell 2014) - we expect the number of tourists to be high. Therefore, their aggregate input in the feedback system is essential for the business model. Second, they purchase the company's products, though this must be prompted by marketing efforts. Our participants admitted that their return to the site was due to reminders, not through involvement with the collective processes or ongoing commitment to the brand. Thus it can be assumed they provide value for the firm as a mass client base.

\section{CONCLUSION: MANAGING COMMUNITIES OF CO-CREATION AROUND PARTICIPATION STYLES}

Our findings build on existing research on co-creation by looking at this phenomenon with a multistakeholder perspective on value creation, not just from the company's point of view. Our research contributes to the literature by showing how co-creation community members with different engagement styles contribute to the value chain while also deriving value from this participation. We show that Kozinets's (1999) discussion on e-tribalized marketing is still relevant, albeit requiring some adjustments to fit new contexts. Our findings also have implications for theories on brand communities. We show that the context through which brand community connections are established can extend backward through the brand value chain. With cocreation, end purchase and use of the brand are not always a prerequisite for community affiliation and that participa- tion in co-creation can be an end in and of itself. Therefore, people form connections with the brand while participating in its creation, not just in a post-production context. Our findings on how value is created for the firm by community members with different engagement orientations also answer Payne et al.'s (2008) quest for mapping competences in the value-creation process and managing encounter processes where company and customers (and customers and customers) interact. In figure 4, we summarize how firms could better tailor their community management practices to maximize competencies while maintaining heterogeneity across members.

\section{Sustain the Engagement Levels of Communals for Maximum Connections}

The key to managing communals is to maintain their community connections and skills. They strive to maintain and further generate social capital; thus, facilitating interaction between these members is crucial to the success of a firm. The platforms should be set up to have brand-related conversations, with room for off-topic interactions, thus allowing individuals to generate stronger bonds that go beyond the task. As they build connections, communals are creating value for the firm by acting as brand ambassadors. By socializing with other members on brand-related platforms, they are practicing empathy (Schau et al. 2009). Second, communals are motivated by acquisition and deployment of skills. Companies need to highlight individual achievements publicly and facilitate features to disseminate knowledge and skills to increase member capacities. For example, Threadless has successfully designed a feature on their website that displays winners' screen names next to their designs. This is how communals can badge and milestone, two practices described by Schau et al. (2009).

\begin{tabular}{|c|c|}
\hline $\begin{array}{c}\text { Aspirers } \\
\text { (Focus on skill building, maintain } \\
\text { community orientation) }\end{array}$ & $\begin{array}{c}\text { Communals } \\
\text { (Maintain skill and community } \\
\text { orientations) }\end{array}$ \\
\hline $\begin{array}{c}\text { Tourists } \\
\text { (First focus on community } \\
\text { building, then add skills) }\end{array}$ & $\begin{array}{c}\text { Utilizers } \\
\text { (Unlimited skill building, be } \\
\text { conservative about increasing } \\
\text { community orientation) }\end{array}$ \\
\hline
\end{tabular}

Figure 4. Recommended strategies for tailoring community management practices for different engagement styles. 
Communals provide the highest value for the firm; our data show that they have the strongest attachment to the community, they frequently submit new designs, and they purchase large quantities of the product. This further affirms Kozinets's (1999) findings that the group he calls insiders represent the most important target for marketers. Communals also feel the need to help other members, often through dispersion of skills to novices. This is done through documenting and empathizing (Schau et al. 2009). The end result is a more stable and wider creator base. Research has shown that participation in co-creation is also found to amplify customer satisfaction, or dissatisfaction in the case of failed services (Heidenreich et al. 2014). In a similar vein, we recommend that community managers build opportunities for communals to participate in problem-solving tasks that might go beyond creating designs, so as to maintain their commitment and acknowledge their voice in community building.

\section{Provide Creative Control to Conservatively Connect Utilizers}

Utilizers bring value to the firm and community members through an influx of new ideas and the customization of the brand through creative diversity that might not be offered by other members. By choosing not to conform to the brand communities' standards, utilizers are continuously evolving the brand in directions where more orthodox communals might not go. This is in line with research that argues that clustering results in social learning that produces idea redundancy and reduces innovation (Stephen, Zubcsek, and Goldenberg 2016). Therefore, the weak ties—and even disconnectedness - the utilizers possess within the community are essential in generating innovation. In fact, allowing them to hijack the brand (Wipperfürth 2005; Cova and Pace 2006) will ensure that there is a healthy stream of new ideas that sustain the brand's evolution. Tamisha, a utilizer and designer by trade, quickly became frustrated with Mode Locale's process when she realized she didn't have much control: "I would have liked to gone up to [the city to] see the factory ... it's like I was never involved in my own project." Giving more creative control to utilizers would be beneficial for any co-creation project.

Utilizers continuously customize (Schau et al. 2009) by being creative within the constraints of the task. Companies should embrace their creative spirits by refraining from making participation guidelines too strict or too lax. Although common sense might suggest that greater flexibility would allow participants to express their creativity, we found that one's feeling of freedom of expression increases when stricter guidelines are provided. Participants find it easier to work within a fixed canvas. Threadless regularly holds design challenges restricted by themes and deadlines. These attract user interest, generate new forum boards and discussions, and, as pointed out by both communals and aspirers, link the Threadless aesthetic to divergent topics. Inversely, having too many unknown variables, as was the case for Mode Locale, hinders one's creative spirit, as ideas collide and contradict. This finding is consistent with existing studies that show that creativity is optimized in structured freedom settings (Moreau and Dahl 2005), especially when constraints are designed to underline the core elements of a problem (Sagiv et al. 2010).

\section{Generate Opportunities for Aspirers to Acquire Symbolic Capital}

As discussed above, we find that aspirers purchase the end product in order to associate with the communals and utilizers. Many newcomers will most likely begin their engagement as aspirers; thus, minimizing barriers of entry into communities will retain new users. Threadless overcomes one of these limitations, the lack of skills, by formally providing spaces for co-training and encouraging empathizing (fig. 5). Similarly, unintimidating spaces for socializationsuch as an off-topic area (Ren, Kraut, and Kiesler 2007) can provide a safe zone for those feeling insecure about their lack of skills and looking to bond with members of communities through benevolent conversation. These spaces are used by aspirers to change their discourse: from recreational to informational to social, and finally to relational (Kozinets 1999). Since aspirers are purchasing the product to identify with the brand and its community, companies should emphasize links between community ethos and mythology in their communications to these members. Aspirers also create value for other members as they recognize and reward the utilizers and communals. Therefore, firms need to make efforts to facilitate badging and allow committed aspirerseven when they do not have skills to perform creative tasks themselves - to assess others' skills.

\section{Uncover the Potential of Tourists While Maintaining Heterogeneity}

Tourists, although lacking skills and community motives, are potentially quite numerous and form a customer base. Marketing managers need to facilitate their path into another group if they are interested in building skills or community involvement. In this regard, understanding their needs, in- 


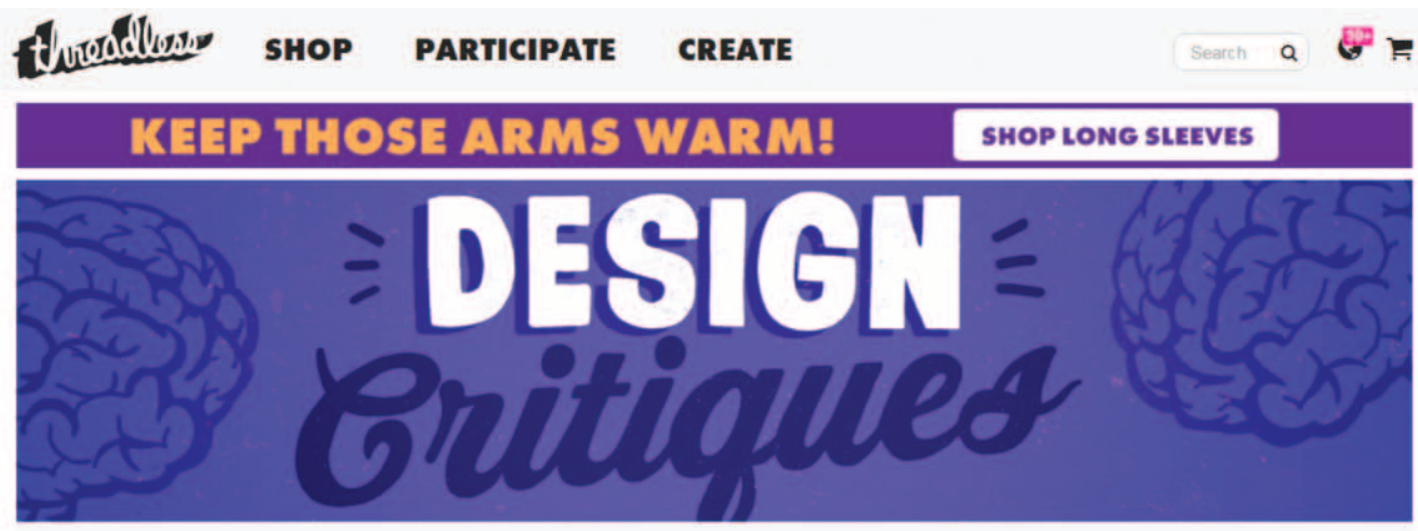

Submit a design for critique

Pick an artist's right brain!

Want to submit for a challenge, but just not sure? Want to open an Artist Shop, but not sure if your art or files are ready for the big time? Good news! You can submit right here and get amazing feedback from your peers in the artist community - and some of the best designers in the world! From color suggestions to concept critiques, get the Threadless magic sparkledust you need to make that nasty apprehension disappear This feature is always available and has no deadline. All designs submitted here can be resubmitted to any Threadless design challenge. So what's stopping you? Remember, you're in the tree of trust here.
YOU COULD WIN Legal stuff

- Valuable feedback on your design from the world's most talented artists

- A spotlight in our blog

- See your score in real time

- Fame and fortune, by having your design chosen for print on Threadless.com!

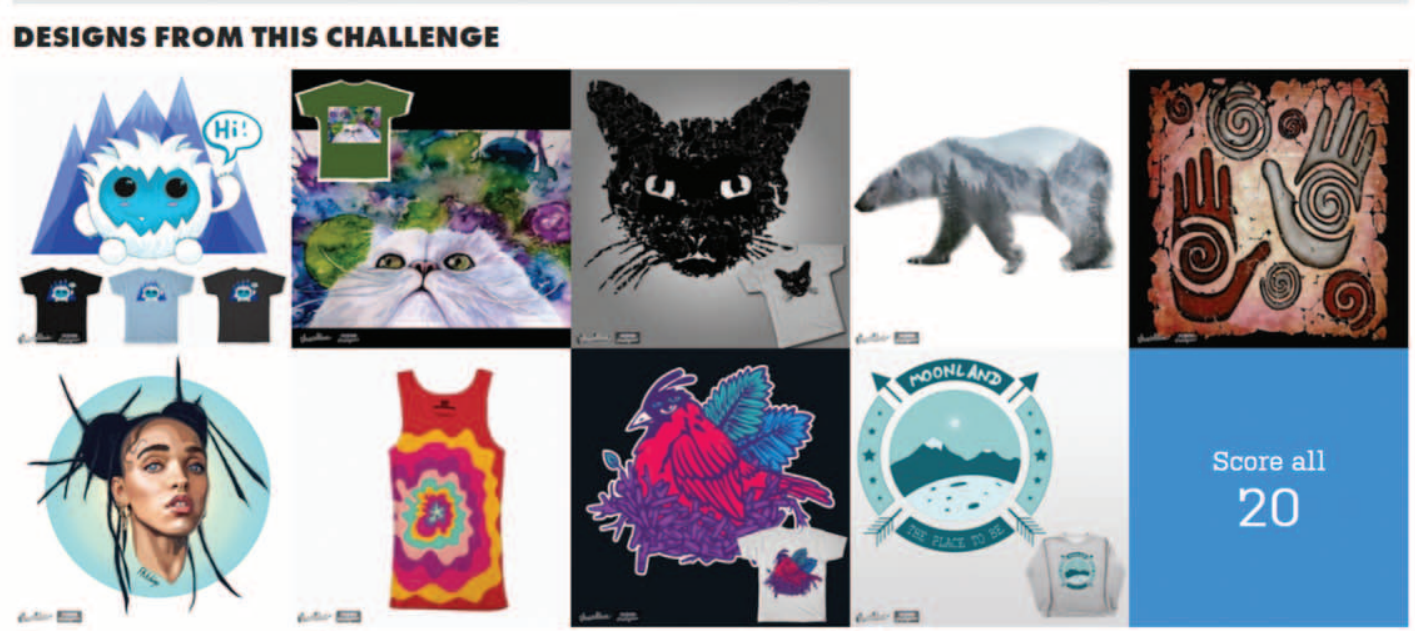

Figure 5. An example of a collaborative training space.

tentions, and longer-term motives will help community managers make better-informed decisions. As the majority of tourists lack the cultural capital to create designs, or the interest to learn these skills, opening paths for them to ascend to the role of aspirers by facilitating community bonding would be an effective solution; however, tutorials and skill building activities can also be extended to tourists should they aim to get more involved in the design process. If they remain tourists, then regular nudging will be necessary to remind them to return to the co-creation platform so that they can vote, comment, or purchase designs.

While the goal of building more skills and community is something we have repeatedly highlighted, our aim is not to say that community managers should attempt to convert all members to communals. Rather, we suggest a careful orchestration of skill- and community-building practices to 


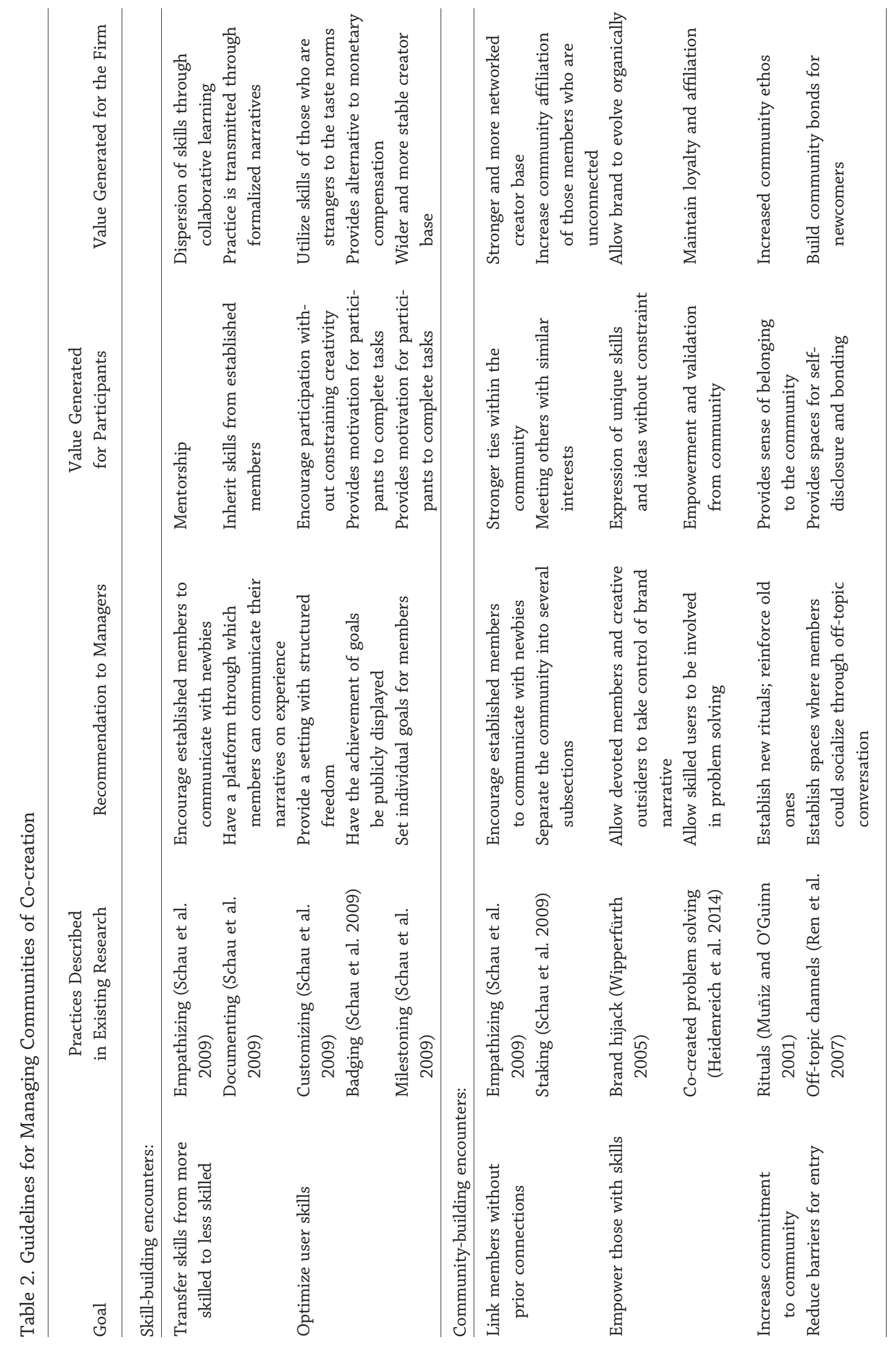


maintain, stabilize, and sustain communities (Thomas, Price, and Schau 2013). A comparison between our two research sites also points to this necessity. Mode Locale, being a very emergent community, consisted mostly of utilizers and tourists, lacking communal bonds and participant motives for skill transfer and resource dependence (Thomas et al. 2013). Without the communals, these two groups were not able to transfer skills, link other members with each other, or perform community-building practices such as rituals. As we believe most emergent communities will start this way, managers need to be proactive in identifying tourists with communal potential and generate community-building encounters to diversify the group's member base early in its life. Table 2 further elaborates on specific practices to achieve community- or skill-building goals and identifies how each generates value for the firm and consumers. Note that these practices have already been identified in prior literature on communities of consumption; therefore, we bridge prior literature on communities to ours.

\section{LIMITATIONS AND FUTURE DIRECTIONS}

Because we were interested in portraying other forms of heterogeneity, we deliberately abstained from discussion on conflict and contestation within communities. We are well aware that communities of aesthetic practice, such as this one, abound with contestation and conflict (Kozinets 2001; Arsel and Bean 2013). Furthermore, although we provide a static portrait, these categories are not completely stable; nor are they exhaustive. We acknowledge that the roles participants can hold can change over time, as they are determined by the amount of cultural and social capital being accumulated, and community bonds are sought and disposed of; thus, the roles are fluid. Therefore, we suggest that future research not only examine conflict within co-creative communities, but also trace members across life cycles as they move from one participation style to another through building skills or community bonds.

We believe this article also opens doors to new measurement and assessment tools for creative communities since it employs two variables that can be easily quantified and measured: skills-based orientation and community orientation. Scales already exist to measure community engagement (Baldus, Voorhees, and Calantone 2015). While skill orientation measurement might be idiosyncratic and dependent on the technical requirements of the task at hand, communities can develop scales based on the type of creativity project. These quantified measures of community affiliation can help managers better understand their customers.

This research has a few participants who were professional designers and artists, some of whom expressed feeling resentment toward co-creation. This is understandable, as crowdsourcing has disrupted many industries. Further research is needed among communities of professionals that have been affected by crowdsourcing to reveal what factors have influenced some professionals to participate and others to refrain. As we discussed, some utilizers would use co-creative communities to advance their careers. Other underlying factors that might be at play are in professional participation.

Our recommendations are built on earlier findings that suggest heterogeneity is necessary in order for communities to innovate and endure (Thomas et al. 2013). While our research has shown how resource dependency operates similarly in communities of co-creation, demonstrating a need for communities to strongly link aspirers to communals while allowing independency for utilizers, a comparative two-case study doesn't allow us to make claims about the optimum configuration of communities in terms of proportion of member types and their connectedness. We therefore suggest that future researchers conduct systematic analyses of co-creation networks to map how tie strength, proportion, and communication between members could matter within a community's life cycle.

\section{REFERENCES}

Algesheimer, René, Utpal M. Dholakia, and Andreas Herrmann (2005), "The Social Influence of Brand Community: Evidence from European Car Clubs," Journal of Marketing, 69 (3), 19-34.

Arsel, Zeynep, and Jonathan Bean (2013), “Taste Regimes and MarketMediated Practice," Journal of Consumer Research, 39 (5), 899-917.

Bagozzi, Richard P., and Utpal M. Dholakia (2006), "Open Source Software User Communities: A Study of Participation in Linux User Groups," Management Science, 52 (7), 1099-1115.

Baldus, Brian J., Clay Voorhees, and Roger Calantone (2015), "Online Brand Community Engagement: Scale Development and Validation," Journal of Business Research, 68 (5), 978-85.

Baldwin, Carliss, and Eric von Hippel (2011), "Modeling a Paradigm Shift: From Producer Innovation to User and Open Collaborative Innovation," Organization Science, 22 (6), 1399-1417.

Beer, David, and Roger Burrows (2010), "Consumption, Prosumption and Participatory Web Cultures: An Introduction," Journal of Consumer Culture, 10 (1), 3-12.

Bourdieu, Pierre (1986/2011), "The Forms of Capital," in Cultural Theory: An Anthology, Oxford: Wiley-Blackwell, 81-93.

Bourdieu, Pierre, and Loïc J. D. Wacquant (1992), An Invitation to Reflexive Sociology, Chicago: University of Chicago Press. 
Brabham, Daren C. (2009), "Crowdsourcing the Public Participation Process for Planning Projects," Planning Theory, 8 (3), 242-62.

_ (2012), "The Myth of Amateur Crowds," Information, Communication and Society, 15 (3), 394-410.

Brodie, Roderick J., Linda D. Hollebeek, Biljana Juric, and Ana Ilic (2011), "Customer Engagement: Conceptual Domain, Fundamental Propositions, and Implications for Research," Journal of Service Research, 14 (3), 252-71.

Brodie, Roderick J., Ana Ilic, Biljana Juric, and Linda Hollebeek (2013), "Consumer Engagement in a Virtual Brand Community: An Exploratory Analysis," Journal of Business Research, 66 (1), 105-14.

Campbell, Colin (2005), "The Craft Consumer," Journal of Consumer Culture, 5 (1), 23-42.

Cauquelin, Anne (2003), L'exposition De Soi: Du Journal Intime Aux Webcams, Paris: Estel.

Chafkin, Max (2008), “The Customer Is the Company," Inc., 30 (6), 88.

Conley, Caryn, and Jennifer Tosti-Kharas (2014), "Crowdsourcing Content Analysis for Managerial Research,” Management Decision, 52 (4), $675-88$.

Cova, Bernard, and Daniele Dalli (2009), "Working Consumers: The Next Step in Marketing Theory?" Marketing Theory, 9 (3), 315-39.

Cova, Bernard, and Stefano Pace (2006), "Brand Community of Convenience Products: New Forms of Customer Empowerment-the Case 'My Nutella the Community,'” European Journal of Marketing, 40 (9/ 10), 1087-1105.

Djelassi, Souad, and Isabelle Decoopman (2013), "Customers' Participation in Product Development through Crowdsourcing: Issues and Implications," Industrial Marketing Management, 42 (5), 683-92.

Etgar, Michael (2006), "Co-production of Services," in The ServiceDominant Logic of Marketing: Dialog, Debate, and Directions, ed. Robert Lusch and Stephen L. Vargo, Abingdon: Routledge.

- (2008), "A Descriptive Model of the Consumer Co-production Process," Journal of the Academy of Marketing Science, 36 (1), 97-108.

Heidenreich, Sven, Kristina Wittkowski, Matthias Handrich, and Tomas Falk (2014), "The Dark Side of Customer Co-creation: Exploring the Consequences of Failed Co-created Services," Journal of the Academy of Marketing Science, 43 (3), 279-96.

Hossain, Mokter, and Ilkka Kauranen (2015), "Crowdsourcing: A Comprehensive Literature Review," Strategic Outsourcing: An International Journal, 8 (1), 2-22.

Howe, Jeff (2006), “The Rise of Crowdsourcing," Wired, 14 (June), 5. (2008), Crowdsourcing: Why the Power of the Crowd Is Driving the Future of Business, New York: Crown Business.

Humphreys, Ashlee, and Kent Grayson (2008), "The Intersecting Roles of Consumer and Producer: A Critical Perspective on Co-production, Cocreation and Prosumption," Sociology Compass, 2 (3), 963-80.

Kleemann, Frank, G., Günter Voß, and Kerstin Rieder (2008), “Un(der)paid Innovators: The Commercial Utilization of Consumer Work through Crowdsourcing," Science, Technology and Innovation Studies, 4 (1), 526.

Kohler, Thomas (2015), "Crowdsourcing-Based Business Models," California Management Review, 57 (4), 63-84.

Kozinets, Robert V. (1999), "E-Tribalized Marketing? The Strategic Implications of Virtual Communities of Consumption," European Management Journal, 17 (3), 252-64.

(2001), "Utopian Enterprise: Articulating the Meanings of Star Trek's Culture of Consumption," Journal of Consumer Research, 28 (1), $67-88$.
_ (2002), "The Field Behind the Screen: Using Netnography for Marketing Research in Online Communities," Journal of Marketing Research, 39 (1), 61-72.

(2009), Netnography: Doing Ethnographic Research Online, London: Sage.

Kozinets, Robert V., Andrea Hemetsberger, and Hope Jensen Schau (2008), "The Wisdom of Consumer Crowds: Collective Innovation in the Age of Networked Marketing," Journal of Macromarketing, 28 (4), 339-54.

Lusch, Robert F., and Stephen L. Vargo (2006), "Service-Dominant Logic: Reactions, Reflections and Refinements," Marketing Theory, 6 (3), 28188.

Mahr, Dominik, and Annouk Lievens (2012), "Virtual Lead User Communities: Drivers of Knowledge Creation for Innovation," Research Policy, 41 (1), 167-77.

Mathwick, Charla, Caroline Wiertz, and Ko De Ruyter (2008), "Social Capital Production in a Virtual P3 Community," Journal of Consumer Research, 34 (6), 832-49.

McAlexander, James H., John W. Schouten, and Harold F. T. Koenig (2002), "Building Brand Community," Journal of Marketing, 66 (1), 38-54.

Mladenow, Andreas, Christine Bauer, and Christine Strauss (2014), "Social Crowd Integration in New Product Development: Crowdsourcing Communities Nourish the Open Innovation Paradigm," Global Journal of Flexible Systems Management, 15 (1), 77-86.

Moreau, C. Page, and Darren W. Dahl (2005), "Designing the Solution: The Impact of Constraints on Consumers' Creativity," Journal of Consumer Research, 32 (1), 13-22.

Muñiz, Albert M., and Thomas C. O'Guinn (2001), "Brand Community," Journal of Consumer Research, 27 (4), 412-32.

Nahapiet, Janine, and Sumantra Ghoshal (1998), "Social Capital, Intellectual Capital, and the Organizational Advantage," Academy of Management Review, 23 (2), 242-66.

Nickell, Jake (2014), "How a Small Idea Could Have a Big Payoff," https:// www.fastcompany.com/3031540/how-a-small-idea-could-have-a-big -payoff.

O'Hern, Matthew, and Aric Rindfleisch (2010), “Customer Co-creation: A Typology and Research Agenda," Review of Marketing Research, 6, 84106.

Parmentier, Marie-Agnès, Eileen Fischer, and A. Rebecca Reuber (2013), "Positioning Person Brands in Established Organizational Fields," Journal of the Academy of Marketing Science, 41 (3), 373-87.

Payne, Adrian F., Kaj Storbacka, and Pennie Frow (2008), "Managing the Co-creation of Value," Journal of the Academy of Marketing Science, 36 (1), 83-96.

Prahalad, Coimbatore K., and Venkatram Ramaswam (2000), "Co-opting Customer Competence," Harvard Business Review, 78 (1), 79-90.

Ren, Yuqing, Robert Kraut, and Sara Kiesler (2007), "Applying Common Identity and Bond Theory to Design of Online Communities," Organization Studies, 28 (3), 377-408.

Roth, Yannig, Daren C. Brabham, and Jean-François Lemoine (2015), "Recruiting Individuals to a Crowdsourcing Community: Applying Motivational Categories to an Ad Copy Test," in Advances in Crowdsourcing, ed. Fernando J. Garrigos-Simon, Ignacio Gil-Pechuán, and Sofia Estelles-Miguel, Berlin: Springer, 15-31.

Sagiv, Lilach, Sharon Arieli, Jacob Goldenberg, and Ayalla Goldschmidt (2010), "Structure and Freedom in Creativity: The Interplay between Externally Imposed Structure and Personal Cognitive Style," Journal of Organizational Behavior, 31 (8), 1086-110. 
Schau, Hope Jensen, Albert M. Muñiz, and Eric J. Arnould (2009), "How Brand Community Practices Create Value," Journal of Marketing, 73 (5), 30-51.

Schenk, Eric, and Claude Guittard (2011), "Towards a Characterization of Crowdsourcing Practices," Journal of Innovation Economics, 1 (7), 93107.

Schouten, John W., and James H. McAlexander (1995), "Subcultures of Consumption: An Ethnography of the New Bikers," Journal of Consumer Research, 22 (1), 43-61.

Spiggle, Susan (1994), "Analysis and Interpretation of Qualitative Data in Consumer Research," Journal of Consumer Research, 21 (3), 491-503.

Stephen, Andrew T., Peter Pal Zubcsek, and Jacob Goldenberg (2016), "Lower Connectivity Is Better: The Effects of Network Structure on Redundancy of Ideas and Customer Innovativeness in Interdependent Ideation Tasks," Journal of Marketing Research, 53 (2), 263-79.

Terwiesch, Christian, and Karl T. Ulrich (2009), Innovation Tournaments: Creating and Selecting Exceptional Opportunities, Cambridge, MA: Harvard Business Press.

Thomas, Tandy Chalmers, Linda L. Price, and Hope Jensen Schau (2013), "When Differences Unite: Resource Dependence in Heterogeneous Consumption Communities," Journal of Consumer Research, 39 (5), 101033.

Thompson, Craig J. (1997), "Interpreting Consumers: A Hermeneutical Framework for Deriving Marketing Insights from the Texts of Consumers' Consumption Stories," Journal of Marketing Research, 34 (4), $438-55$.

Threadless (2015), “Threadless Live," http://www.threadless.com/live.
Van Doorn, Jenny, Katherine N. Lemon, Vikas Mittal, Stephan Nass, Doreén Pick, Peter Pirner, and Peter C. Verhoef (2010), "Customer Engagement Behavior: Theoretical Foundations and Research Directions," Journal of Service Research, 13 (3), 253-66.

Vargo, Stephen L., and Robert F. Lusch (2016), "Institutions and Axioms: An Extension and Update of Service-Dominant Logic," Journal of the Academy of Marketing Science, 44 (1), 5-23.

Vargo, Stephen L., Paul P. Maglio, and Melissa Archpru Akaka (2008), "On Value and Value Co-creation: A Service Systems and Service Logic Perspective," European Management Journal, 26 (3), 145-52.

Vivek, Shiri D., Sharon E. Beatty, and Robert M. Morgan (2012), "Customer Engagement: Exploring Customer Relationships beyond Purchase," Journal of Marketing Theory and Practice, 20 (2), 122-46.

Von Hippel, Eric (2009), "Democratizing Innovation: The Evolving Phenomenon of User Innovation," International Journal of Innovation Science, 1 (1), 29-40.

Wiertz, Caroline, and Ko de Ruyter (2007), "Beyond the Call of Duty: Why Customers Contribute to Firm-Hosted Commercial Online Communities," Organization Studies, 28 (3), 347-76.

Wipperfürth, Alex (2005), Brand Hijack: Marketing without Marketing, New York: Portfolio.

Xie, Chunyan, Richard Bagozzi, and Sigurd Troye (2008), “Trying to Prosume: Toward a Theory of Consumers as Co-creators of Value," Journal of the Academy of Marketing Science, 36 (1), 109-22.

Zhao, Yuxiang, and Qinghua Zhu (2014), "Evaluation on Crowdsourcing Research: Current Status and Future Direction," Information Systems Frontiers, 16 (3), 417-34. 